03.4;04.1

\title{
Измерение количества вещества, испаряемого с поверхности вязкой диэлектрической жидкости при наносекундном барьерном разряде
}

\author{
(C) Н.Г. Данченко ${ }^{1}$, А.Е. Дубинов ${ }^{1-3, \uparrow}$, Ю.П. Кожаева ${ }^{1-3}$ \\ ${ }^{1}$ Российский федеральный ядерный центр - Всероссийский \\ научно-исследовательский институт экспериментальной фризики, Саров, \\ Нижегородская обл., Россия \\ ${ }^{2}$ Национальный исследовательский ядерный университет „МИФИ“, \\ Москва, Россия \\ ${ }^{3}$ Саровский фризико-технический институт, Саров, Нижегородская обл., \\ Россия \\ 『E-mail: dubinov-ae@yandex.ru
}

Поступило в Редакцию 26 июня 2018 г.

Впервые измерено количество вещества, испаряемого с поверхности вязкой диэлектрической жидкости при наносекундном барьерном разряде. Метод измерения основан на создании в объеме жидкости газового микропузырька и последующей генерации в нем разряда. В результате по увеличению радиуса микропузырька в процессе разряда можно определить количество вещества, испарившегося с его стенки. Показано, что при миллиджоульном энерговкладе в разряд испаряется несколько десятых долей наномолей и с ростом энерговклада количество испаряемого вещества возрастает.

DOI: 10.21883/PJTF.2018.20.46801.17438

Диэлектрический барьерный разряд (ДБР), т.е. электрический разряд, возникающий под действием напряжения в газе при условиях, когда хотя бы один из электродов покрыт слоем жидкого или твердого диэлектрика, широко используется в различных плазмохимических технологиях, технологиях материалов и плазменной медицины [1-3]. Он представляет собой сложный многофазный электродинамический и плазменно-химический процесс, в котором могут принимать участие вещества, находящиеся сразу в четырех агрегатных состояниях, причем 
некоторые порции веществ могут переходить из одного агрегатного состояния в другое.

Экспериментальные исследования ДБР часто весьма трудоемки по причине малости размеров плазмы ДБР (часто менее $\mathrm{mm}$ ) и скоротечности процесса ( $\mu$ s и менее). Поэтому любые достоверные результаты измерений, полученные при исследованиях ДБР, могут представлять научную и практическую ценность.

В настоящей работе приведены результаты измерений количества вещества, испаряемого ДБР с поверхности диэлектрического барьера в случае, когда барьер представляет собой вязкую жидкость. Такие измерения необходимы, например, для расчета эффективности и ресурса работы приборов, основанных на ДБР.

Метод измерений основан на создании в объеме жидкости газовых микропузырьков и осуществлении затем в них импульсных ДБР. Тогда по увеличению радиуса микропузырьков в процессе импульса ДБР можно судить о количестве вещества, испарившегося с его стенки.

Рассмотрим пример реализации метода, когда в качестве вязкой жидкости выбран пчелиный мед. Пчелиный мед является очень удобной средой для демонстрации предлагаемого метода вследствие его большой вязкости, при которой микропузырьки практически неподвижны, малой электропроводности, что важно для генерации самого ДБР, и оптической прозрачности, обеспечивающей наблюдение за микропузырьками с высоким пространственным разрешением.

Пчелиный мед представляет собой, как известно, сильновязкую жидкость желто-коричневого цвета. Физические свойства меда зависят от места его сбора и условий хранения. Согласно [4-7], жидкий мед может иметь следующие физические свойства: плотность $\rho=1.41-1.51 \mathrm{~kg} / \mathrm{m}^{3}$, влагосодержание $\eta=20-25 \%$, водородный показатель $\mathrm{pH}=3.1-4.5$, электропроводность $\sigma=0.1-1.1 \mathrm{mS} / \mathrm{cm}$. Вязкость меда сильно зависит от температуры, она может принимать значение из диапазона $v=10-30 \mathrm{~Pa} \cdot \mathrm{s}$ при комнатной температуре [5]. Важной для данного метода величиной оказался также коэффициент поверхностного натяжения меда $\alpha$. Согласно [8], эта величина варьируется незначительно при вариации состава меда, температуры и влажности: от 0.3 до $0.32 \mathrm{~N} / \mathrm{m}$.

В настоящей работе использовался натуральный пчелиный мед российской фирмы „Medovaya Dolina LLC“ [9], находящийся в жидком состоянии. Ранее мед этой марки использовался в исследованиях кристаллизации сахаров под действием наносекундных искровых разря-

Письма в ЖТФ, 2018, том 44, вып. 20 


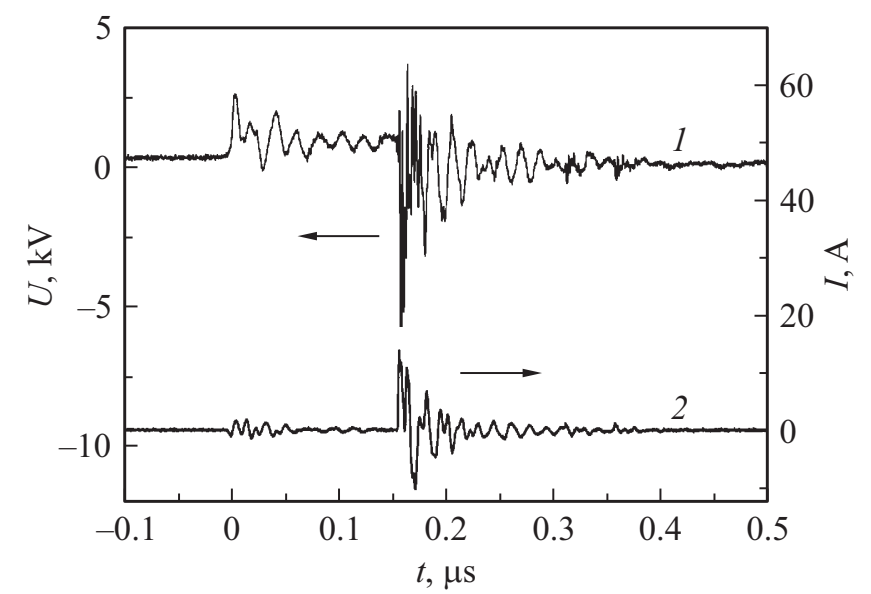

Рис. 1. Типичные синхронизированные осциллограммы импульсов напряжения (1) и полного тока (2) наносекундного искрового разряда от генератора ESIG-010.

дов [10], в нем также отрабатывалась техника оптической визуализации ДБР внутри газовых микропузырьков [11].

Для генерации микропузырька в объеме лежащей на подложке капли меда осуществлялся однократный наносекундный электрический пробой при помощи пьезоэлектрического генератора искр ESIG-010, подключенного к игольчатым электродам через последовательно соединенный ограничивающий резистор с сопротивлением $R$. Электроды были изготовлены из нержавеющей стали и погружены в каплю. Типичные осциллограммы импульсов напряжения и полного тока генератора в несогласованном режиме искрового разряда при $R=9.1 \Omega$ показаны на рис. 1 .

В результате пробоя в объеме капли образуется сферический микропузырек радиусом $r=250-400 \mu \mathrm{m}$, наполненный парами меда. Вследствие большой вязкости меда микропузырек имеет постоянный радиус и остается неподвижным в течение нескольких часов, что позволяет тщательно подготовиться к следующей стадии процесса настроить положение электродов для генерации ДБР внутри микропузырька и систему визуализации.

Письма в ЖТФ, 2018, том 44, вып. 20 


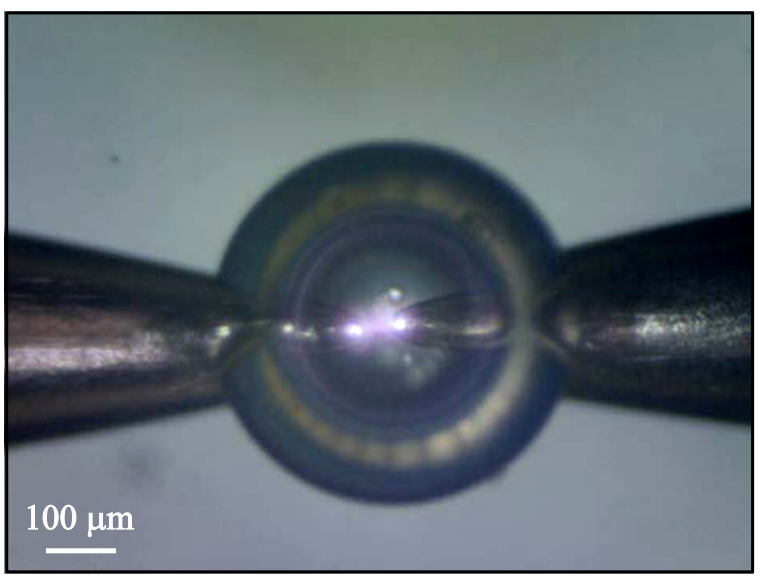

$a$

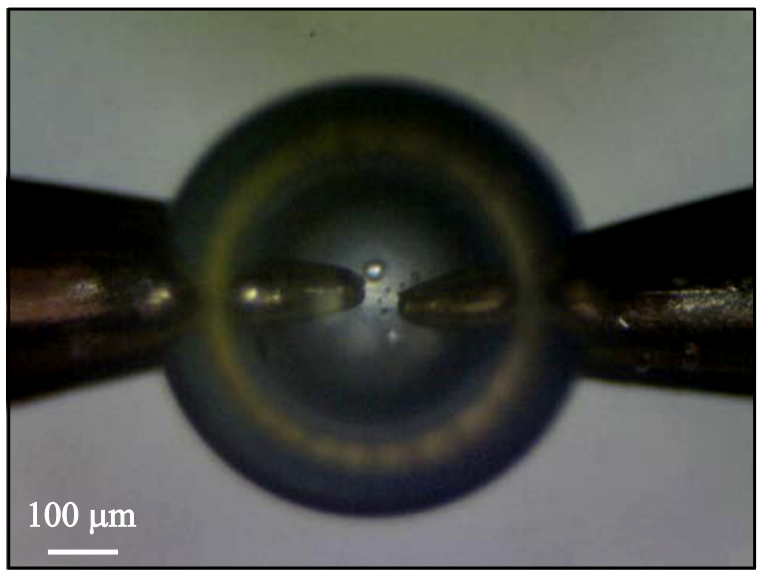

Рис. 2. Фотоизображения микропузырька в меде. $a-$ в момент разряда, $b$ - после разряда.

Для визуализации микропузырька и разрядных процессов в нем использовался оптический микроскоп Levenhuk D50L NG, оснащенный цифровой видеокамерой DEM200. Наибольшее увеличение оптической системы микроскопа составляет $640 \times$, а с дополнительной линзой

2 Письма в ЖТФ, 2018, том 44, вып. 20 
Барлоу $-1280 \times$. Получаемые изображения имеют высокое разрешение $(1600 \times 1200$ пикселей $)$.

Эксперименты проводились в воздухе атмосферного давления ( $p_{a t m}=750$ Torr) при температуре $T=21^{\circ} \mathrm{C}$. Было получено более сотни изображений микропузырьков с ДБР и без разряда, по которым измерялся диаметр микропузырька как до, так и после разряда. Типичные изображения микропузырька во время разряда и после него с увеличенным диаметром показаны на рис. $2, a, b$.

На них электроды находятся за микропузырьком и не заходят внутрь него, поэтому разряд можно считать барьерным. Аргументы, поясняющие, почему и как внутри газовых пузырей в жидкости формируется именно ДБР, представлены в [11,12]. Некоторые особенности изображений, такие как зеркальное кольцо и уменьшение изображений внутри кольца в 1.6 раз (для данной марки меда), описаны в [11].

Статическое газовое давление внутри микропузырька, как известно, складывается из трех составляющих: атмосферного давления окружающего каплю воздуха, гидростатического давления столба жидкости над микропузырьком и давления, обусловленного поверхностным натяжением:

$$
p=p_{a t m}+\rho g h+\frac{2 \alpha}{r} .
$$

Сравнение численных величин в условиях наших экспериментов показало, что в (1) определяющая роль принадлежит атмосферному давлению, в то время как два оставшихся слагаемых на несколько порядков меньше. По этой причине статическое давление газа в пузырьке можно считать атмосферным, а количество вещества, испаряемого со стенок микропузырька при ДБР, пропорционально приросту объема микропузырька $\Delta V$.

После статистического анализа всех изображений было замечено, что прирост объема микропузырька $\Delta V$ за один импульс ДБР зависит от сопротивления $R$ ограничительного резистора; следовательно, он также зависит от электрического энерговклада в разряд $E$. В то же время никакой зависимости $\Delta V$ от начального объема микропузырька выявлено не было.

Количества вещества $\Delta z$, добавляемого в микропузырек при испарении меда для конкретного импульса ДБР, можно вычислить из уравнения состояния идеального газа Клапейрона, записанного в виде

Письма в ЖТФ, 2018, том 44, вып. 20 


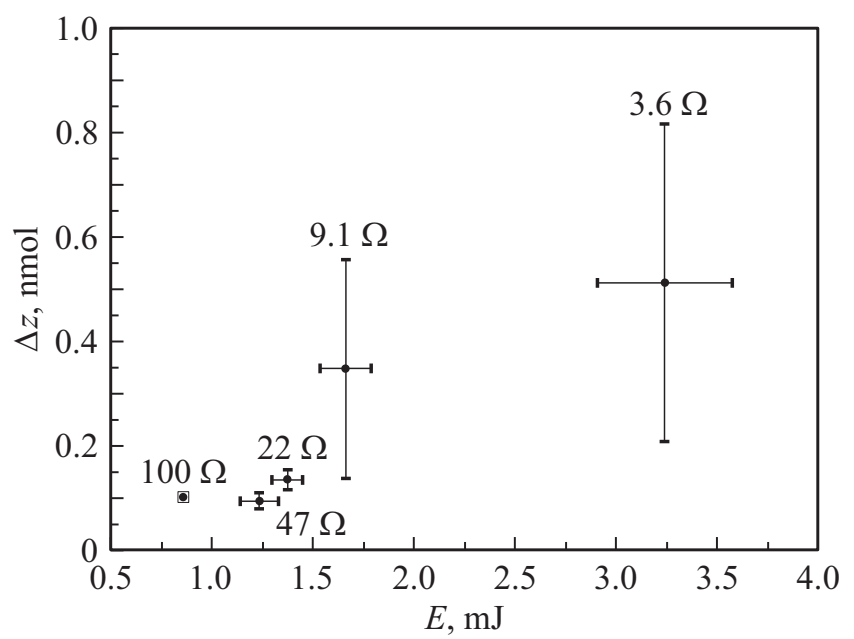

Рис. 3. Зависимость $\Delta z(E)$.

разницы величин после и до разрядного импульса:

$$
\frac{p_{a t m} \Delta V}{R_{0} T}=\Delta z
$$

где $R_{0}$ - газовая постоянная.

Измерения проводились для пяти значений сопротивления $R$ ограничительного резистора: $3.6,9.1,22,47,100 \Omega$. Для каждого значения сопротивления записывалось по десять пар синхронизированных осциллограмм тока и напряжения типа тех, что показаны на рис. 1. По осциллограммам определялся энерговклад в разряд по формуле

$$
E=\int_{t_{\text {pulse }}}|U||I| d t .
$$

По результатам вычислений (2) и (3) была построена зависимость $\Delta z(E)$. Она представлена на рис. 3 .

Погрешности были вычислены путем статистической обработки по десяти реализациям для каждой точки. Для $E$ они определяются нестабильностью от импульса к импульсу работы пьезоэлектрического

2* Письма в ЖТФ, 2018, том 44, вып. 20 
генератора искр ESIG-010, для $\Delta z-$ погрешностью расположения концов электродов относительно микропузырька и как следствие разбросом длины плазменного канала внутри него.

Исходя из рис. 3 можно заключить следующее.

1. При миллиджоульном энерговкладе в разряд испаряется несколько десятых долей наномолей.

2. С ростом сопротивления $R$ ограничительного резистора энерговклад в разряд уменьшается.

3. С ростом энерговклада в разряд растет количество испаряемого вещества.

Таким образом, в работе предложен и реализован прямой метод измерения количества вещества, испаряемого в импульсном ДБР, когда барьером является жидкость.

\section{Список литературы}

[1] Самойлович В.Г., Гибалов В.И., Козлов К.В. Физическая химия барьерного разряда. М.: Изд-во МГУ, 1989. 176 с.

[2] Kogelschatz U. // Plasma Chem. Plasma Proc. 2003. V. 23. N 1. P. 1-46.

[3] Автаева С.В. Барьерный разряд. Исследование и применение. Бишкек: Изд-во КРСУ, 2009. 152 с.

[4] Szczęsna T., Rybak-Chmielewska H. // J. Apicult. Sci. 2004. V. 48. N 2. P. 97-102.

[5] Kayacier A., Karaman S. // J. Texture Studies. 2008. V. 39. N 1. P. 17-27.

[6] Saxena S., Gautam S., Sharma A. // Food Chem. 2010. V. 118. N 2. P. 391-397.

[7] A-Rahaman N.L., Chua L.S., Sarmidi M.R., Aziz R. // Agricult. Sci. 2014. V. 4. N 5B. P. 46-51.

[8] Oroian M. // J. Food Eng. 2013. V. 119. N 1. P. 167-172.

[9] Medovaya Dolina LLC; http://www.medovayadolina.com/

[10] Dubinov A.E., Kozhayeva J.P., L'vov I.L., Sadovoy S.A., Selemir V.D., Vyalykh D.V. // Cryst. Growth Design. 2015. V. 15. N 10. P. 4975-4978.

[11] Dubinov A.E., Kozhayeva J.P., Danchenko N.G. // IEEE Trans. Plasma Sci. 2018. V. 46. N 8. P. 2930-2934.

[12] Gershman S., Mozgina O., Belkind A. Becker K., Kunhardt E. // Contrib. Plasma Phys. V. 47. N 1-2. P. 19-25. 